\title{
Beyond the Nuclear Family: An Evolutionary Perspective on Parenting
}

\section{Current Opinion in Psychology: \\ http://www.sciencedirect.com/science/article/pii/S2352250X15002080}

\author{
Rebecca Sear \\ Department of Population Health, London School of Hygiene and Tropical Medicine, Keppel Street, \\ London WC1E 7HT, UK \\ Email: rebecca.sear@Ishtm.ac.uk
}

Phone: +44 2072994682

\section{$\underline{\text { Abstract }}$}

There has been a recent shift in the evolutionary behavioural sciences towards the view that parenting in our species is cooperative, and that mothers require help from others to raise children successfully. This shift is not yet reflected in psychological models of parenting, which still emphasise the centrality of the nuclear family. This emphasis is problematic both because it neglects the importance of alloparents, and because it assumes the fathering role is consistent across societies. While paternal investment is often substantial in our species, it is also shows considerable ecological variability. This article highlights recent, cross-cultural research on the cooperative nature of human 'parenting', and illustrates the flexible nature of both parenting and alloparenting across human societies.

\section{Introduction}

Parenting in our species is intensive, cooperative and flexible. Human newborns are altricial (helpless), requiring intensive investment, and childhood is long, likely due to the development of skills necessary for the complex subsistence strategies humans adopt [1]. In recent years, the hypothesis that such intensive investment is only possible through cooperative 'parenting' has become established in the evolutionary behavioural sciences: help from allomothers, who may be fathers, grandmothers, siblings and/or other individuals, is required to rear children [2]. Human psychology is adapted, therefore, to a system of parenting where mothers are 'first among equals' in a range of individuals who 'parent' the child. Cooperative childrearing may be a human universal, but the behavioural flexibility of our species, including variation in subsistence, marriage and residence patterns, and relying heavily on social learning, means that the nature of parenting (from mothers and others) varies within and between societies. This article highlights recent research on the cooperative nature of human parenting, emphasising the flexibility of parenting and alloparenting. The theoretical framework underlying this article builds on LeVine and colleagues' [3] model (Figure 1). This assumes parenting/alloparenting shows some species-wide, universal patterns, but also varies, within and between populations, as the result of adaptive adjustment of parenting behaviour to particular ecological conditions (phenotypic plasticity $[4,5]$ ), as well as cultural variation in parenting behaviour (which may or may not be adaptive).

\section{Alloparenting}


The mother is the primary caregiver to human newborns, and throughout the vast majority of human history was vital to the infant's survival at least until the infant was capable of surviving without breastmilk [6]. But the weight of empirical evidence now demonstrates that alloparenting, of both infants and older children, is common and has beneficial effects on children [7]. This suggests that too much emphasis has been placed in Western psychology on the parenting role of the mother, in exclusion to other carers. Henrich and colleagues have criticised psychologists for over-emphasising research on WEIRD (Western, Educated, Industrialised, Rich and Democratic) societies [8]. Recent research has explicitly criticised psychological models of parenting and child development for this same shortcoming - in particular, for developing models of mother-infant attachment that rely too heavily on cultural norms of parenting as observed in the Western middle classes around the middle of the $20^{\text {th }}$ century, the period when influential theories about parenting were developed [9]. Family structures were rather weird in WEIRD societies at this time: an extreme form of the nuclear family was considered normative, where family units consisted of mother, father and children; other family members often lived some distance away; and there was an unusually rigid division of labour where mothers were considered largely responsible for reproductive labour and fathers for productive labour. Evolutionary theories of parenting based on a narrow slice of humanity are problematic, and the challenges to these theories presented by cross-cultural research have recently been clearly articulated [10-12].

Human family systems are unusually flexible [13]. Some form of pair-bond is typical, but mothers and fathers may be monogamously, polygynously or, occasionally, polyandrously partnered, and may or may not live in the same household; extended families are common, where mothers live with, or in close proximity to, grandparents and are embedded in social networks rich in other kin; and, while divisions of labour exist, they are such that women are often responsible for substantial subsistence labour [14]. Such family organisation both requires, and allows for, substantial allomaternal care of children, so that children may form attachment relationships with several individuals [15]. Family relationships may vary flexibly within populations, as well as between them, so that parents and alloparents can optimise their investment across all dependent children, and in response to the children's needs and their own ability to invest [16].

A longitudinal study of Aka foragers in central Africa demonstrates just how flexible parenting can be, even within a homogenous hunter-gatherer society [17]. While it has been known for some time that even infants are cared for by multiple caretakers in hunter-gatherer societies, research on the Aka shows that the caretaking activities of fathers, grandmothers, siblings and other individuals are responsive both to the mother's needs and the availability of other sources of help. The grandmother is the most important allocarer, but care from other social network members can be substituted in her absence [18]. Allocarers also reduce mother's allocation of time to childcare and energy expenditure, as predicted by the cooperative breeding hypothesis [19]. Part of this repertoire of flexible parenting may be the ability of parents to delegate responsibility to other individuals entirely. Elsewhere in Africa, foster care by kin has been interpreted as 'dispersed cooperative breeding', which allows mothers to strategically reduce investment in certain children while ensuring children are cared for those with a vested interest in raising them ([20] see also [21] [22]).

Allomaternal care is a human universal. Grandparenting is still common in WEIRD societies [23]: across 11 European countries $44 \%$ of grandparents provided childcare for their grandchildren, with some variation across countries (the figure was $63 \%$ in the UK [24]). Some variation in grandparental 
investment in WEIRD contexts can be explained through biological factors: genetic relatedness between grandparents and grandchildren matters [25]. Grandparenting can also help women balance their productive and reproductive demands [26], and can be substituted for paternal care [27], as in Aka foragers. Some variation may be a response to different cultural and policy regimes in different parts of Europe, however: grandparents more commonly provide intensive childcare in regions of Europe where conservative family norms are widespread and formal (state-provided or paid-for) childcare is less readily available [28].

One common carer in non-WEIRD societies is not available to WEIRD mothers: older children. This is partly because low fertility means that young children have fewer older siblings to care for them, but also because children are expected to devote time to their education instead of contributing to household labour [29]. This may have significant implications for child development, if children no longer gain valuable childcare experience and social skills by caring for their younger siblings. Recent research has turned from investigating the impact of care on children to investigating how carers themselves are influenced by parenting relationships [30,31]. The health consequences of parenting are not always positive, but some cognitive benefits have been demonstrated [32,33]. A lack of experience with childrearing may influence subsequent parenting practices in adult life given our species' reliance on social learning [34], even, perhaps surprisingly, for key parenting practices such as breastfeeding $[35,36]$.

\section{Fathering}

Allomaternal care may be a human universal, but paternal investment is not. Recent modelling of the evolution of human life history suggests cooperative breeding and broad cooperative networks may be the most plausible explanation for our species' life history strategy [37]. These results contradict earlier models emphasising the importance of monogamy and paternal provisioning. Human fathers often invest in their offspring [38], more so than the fathers of most species, but there are circumstances under which fathers invest little or nothing. Recent work explaining this variation builds on research by evolutionary biologists Kokko and Jennions $[39,40]$, who have developed theoretical models of why parental care by both mothers and fathers varies (Box 1). For example, this research has stimulated interest in the influence of sex ratios on men's allocation of effort between mating and parenting. A study within a single ethnic group (the Makushi) in south America used variation in sex ratios due to employment patterns to show that men were less interested in uncommitted sex where sex ratios were male-biased [42]. This suggests a bias towards parenting rather than mating effort where men are abundant, in line with Kokko and Jennions' predictions.

Paternity certainty is another variable which may explain variation in paternal effort, and has previously received considerable attention in the evolutionary sciences. Some of this work has made the same error as research on parenting, by assuming that the nuclear family is the universal family form. Such research typically assumes that paternal investment is heavy and universal, but focused exclusively on the man's own children, so that male reproductive strategies are designed to reduce the possibility of cuckoldry. Recent research suggests the need to re-examine some of these assumptions.

In contrast to early evolutionary studies, which often assumed that misattributed paternity is relatively common (likely based on apocryphal stories: [43]), empirical evidence suggests that 
misattributed paternity may not be such a great threat to male reproductive success. Anderson's cross-cultural survey, which found a worldwide average of only $2 \%$ misattributed paternity [44], has now been backed up by recent genetic studies, which estimate rates of misattributed paternity to be $1-2 \%[45,46]$. Low levels of misattributed paternity may indicate low rates of multiple mating by females, perhaps as the result of male reproductive strategies designed to ensure paternity [47]. However, low levels of misattributed paternity may alternatively indicate high levels of multiple mating by females but correct attribution of paternity (which may sometimes mean correctly attributing paternity to be uncertain). Cross-cultural research illustrates that sexual exclusivity within marriages is not a human universal, neither for men nor women [48], and that polyandrous matings are socially sanctioned in a wider range of societies than previously thought ([49], see [50] for an example). Paternity uncertainty may be somewhat higher in such polyandrous populations than in populations where husbands expect exclusive sexual access to their wives, but rates of misattributed paternity (i.e. men wrongly believing a child is their biological offspring) may still be low: men know that their paternity is uncertain if they do not have exclusive sexual access to their partners, and may also be able to assign a rough estimate of paternity certainty. For example, 'partible paternity' societies are common in South America, where children are believed to have several 'fathers' if their mothers had multiple sexual partners around the time of pregnancy [51]. But often 'primary' and 'secondary' fathers are recognised, with the former being more likely to be the biological father of the child. Overall, this new research suggests that men's reproductive strategies do not always focus on gaining exclusive sexual access to one (or more) mates and investing heavily in her children, but it may sometimes be in men's interests to accept paternity uncertainty.

Note that though paternity uncertainty may influence paternal investment, the relationship between paternity uncertainty and paternal investment is complex, because many other factors also influence paternal investment. While a simplistic assumption might be that men reduce investment in children in societies where paternity is relatively uncertain, this is not necessarily the case. Perhaps counterintuitively, partible paternity societies may be found where the ecology requires particularly high levels of investment from men to provision children: partible paternity may be a strategy by which women gain investment for their children from multiple males [52]. In this case, alloparents are men other than the child's biological father [53] and 'paternal' investment may be directed at children not fathered by the man investing in them. A perspective on parenting that looks beyond the nuclear family therefore reveals examples where men invest little in their children, and where they invest in children other than their own, as well as many examples where men do invest substantially in their offspring despite not living in a nuclear family $[54,55]$.

\section{Mothering}

Comparative cross-cultural research can also help explain variation in mothering. A vignette-study has just been published which was used to explicitly contrast maternal care across WEIRD and nonWEIRD contexts [56]. Clear differences were found between these contexts (Figure 2). In line with evolutionary predictions, hypothetical maternal care decisions were found to be responsive to the mother's reproductive value (her future possible reproductive output), the consequences of the situation for mother and child, and resource access in WEIRD contexts. In non-WEIRD contexts, the most significant factor determining care was the mother's access to resources, with greater resource access predicting greater maternal care, which likely reflects the importance of resource access to child health and survival in low-resource populations [57]. The current state of parenting research 
has now clearly demonstrated how different parenting strategies can be across human populations, and is beginning to produce sufficient high quality research across a range of contexts to allow us to construct a holistic explanation of parenting, including the influence of biological universals, adaptation to different environmental conditions, and cultural differences, as well as how these three components interact to affect parenting behaviour.

\section{Conclusion}

Parenting is an emotive topic, and it is of great interest not just to academics but also to policymakers, the health professions and the general public. An evolutionary, cross-cultural perspective clearly demonstrates considerable variation in parenting behaviour, around some species-typical universals. This should lead to caution when translating academic research into parenting advice or policy $[58,59]$ : 'natural' parental behaviour is often surprisingly flexible, and there are multiple pathways to successful parenting.

\section{Acknowledgements}

Thanks to LSHTM's Evolutionary Demography Group, Laura Brown, Sophie Hedges, David Lawson, Susie Schaffnit, Paula Sheppard and Gert Stulp, and to the editors of this special issue, Steve Gangestad and Josh Tybur, for helpful suggestions.

\section{Annotated bibliography}

[1] H. Kaplan, J.B. Lancaster, W.T. Tucker, K.G. Anderson, Evolutionary approach to below replacement fertility, Am. J. Hum. Biol. 14 (2002) 233-256.

[2] S.B. Hrdy, Mothers and Others: The Evolutionary Origins of Mutual Understanding, Belknap Press, Cambridge, Massachusetts, 2009.

[3] R.A. LeVine, S. Dixon, S.E. LeVine, A. Richman, C. Keefer, P.H. Liederman, et al., The comparative study of parenting., in: Anthropol. Child Dev. A Cross-Cultural Read., Blackwell, Malden, 2008: pp. 55-65.

[4] N.J. Royle, A.F. Russell, A.J. Wilson, The evolution of flexible parenting., Science. 345 (2014) 776-81. *A theoretical discussion of how parenting may adapt to different ecological circumstances, using examples from the biological literature, which unfortunately neglects the human literature but provides an excellent introduction to the evolutionary theory behind flexible parenting.

[5] D. Nettle, M.A. Gibson, D.W. Lawson, R. Sear, Human behavioral ecology: current research and future prospects, Behav. Ecol. 24 (2013) 1031-1040.

[6] S.B. Hrdy, Mother Nature: Maternal Instincts and the Shaping of the Species, Vintage, London, 2000.

[7] R. Sear, R. Mace, Who keeps children alive? A review of the effects of kin on child survival, Evol. Hum. Behav. 29 (2008) 1-18.

[8] J. Henrich, S.J. Heine, A. Norenzayan, The weirdest people in the world?, Behav. Brain Sci. 33 (2010) 61-83. 
[9] R.A. LeVine, Attachment theory as cultural ideology, in: Differ. Faces Attach. Cult. Var. a Univers. Hum. Need, 2014: pp. 50-65. ${ }^{* *}$ A clear articulation of the culturally-biased nature of attachment theory, from an author with a lifetime's experience of research in crosscultural parenting.

[10] H. Otto, H. Keller, Different Faces of Attachment: Cultural Variations on a Universal Human Need, Cambridge University Press, 2014. ${ }^{* *}$ Valuable detail of the cross-cultural similarities and differences found in infant attachment, with examples from many different cultural contexts

[11] D.F. Lancy, "Teaching is so WEIRD," Behav. Brain Sci. 38 (2015) e48.

[12] D.F. Lancy, The Anthropology of Childhood: Cherubs, Chattel, Changelings, Cambridge University Press, 2014.

[13] R.S. Walker, K.R. Hill, M. V Flinn, R.M. Ellsworth, Evolutionary history of hunter-gatherer marriage practices, PLoS One. 6 (2011) e19066.

[14] B.S. Hewlett, Culture, history and sex: anthropological contributions to conceptualizing father involvement, Marriage Fam. Rev. 29 (2000) 59-73.

[15] C.L. Meehan, S. Hawks, Maternal and allomaternal responsiveness: the significant of cooperative caregiving in attachment theory, in: Differ. Faces Attach. Cult. Var. a Univers. Hum. Need, Cambridge University Press, Cambridge, 2014: pp. 113-140.

[16] K. Snopkowski, R. Sear, Grandparental help in Indonesia is directed preferentially towards needier descendants: a potential confounder when exploring grandparental influences on child health., Soc. Sci. Med. 128 (2015) 105-14.

[17] C.L. Meehan, The effects of residential locality on parental and alloparental investment among the Aka foragers of the Central African Republic, Hum. Nat. 16 (2005) 58-80.

[18] C.L. Meehan, C. Helfrecht, R.J. Quinlan, Cooperative breeding and Aka children's nutritional status: is flexibility key?, Am. J. Phys. Anthropol. 153 (2014) 513-25. * Provides empirical data on cooperative breeding in a forager population, including detail on who helps mothers out, from a team with extensive experience and publications on this topic

[19] C.L. Meehan, R. Quinlan, C.D. Malcom, Cooperative breeding and maternal energy expenditure among Aka foragers., Am. J. Hum. Biol. 25 (2013) 42-57.

[20] B.A. Scelza, J.B. Silk, Fosterage as a system of dispersed cooperative breeding: evidence from the Himba., Hum. Nat. 25 (2014) 448-64.

[21] G. Perry, M. Daly, S. Macfarlan, Maternal foster families provide more stable placements than paternal families, Child. Youth Serv. Rev. 46 (2014) 155-159.

[22] P. Sheppard, S.B. Schaffnit, J.R. Garcia, R. Sear, Fostering relations: first sex and marital timings for children raised by kin and non-kin carers, Evol. Hum. Behav. 35 (2014) 161-168.

[23] D.A. Coall, R. Hertwig, Grandparental investment: past, present and future, Behav. Brain Sci. 33 (2010) 1-19. 
[24] K. Glaser, D. Price, G. Di Gessa, E. Ribe, R. Stuchbury, A. Tinker, Grandparenting in Europe: Family Policy and Grandparents' Role in Providing Childcare, 2013.

[25] D.A. Coall, S. Hilbrand, R. Hertwig, Predictors of grandparental investment decisions in contemporary Europe: biological relatedness and beyond., PLoS One. 9 (2014) e84082.

[26] A. Aassve, B. Arpino, A. Goisis, Grandparenting and mothers' labour force participation: A comparative analysis using the Generations and Gender Survey, Demogr. Res. 27 (2012) 5384.

[27] G. Meil, J. Rogero-García, Does paternal childcare replace grandparental support in dualearner families?, Fam. Sci. 6 (2015) 31-37.

[28] M. Jappens, J. Van Bavel, Regional family cultures and child care by grandparents in Europe, Demogr. Res. 27 (2012) 85-120. * Empirical, cross-national study in Europe which provides a detailed analysis of the determinants of grandparental care and how it varies in this region

[29] M.K. Shenk, M.C. Towner, H.C. Kress, N. Alam, A model comparison approach shows stronger support for economic models of fertility decline, Proc. Natl. Acad. Sci. . 110 (2013) 80458050 .

[30] R. Feldman, The adaptive human parental brain: implications for children's social development., Trends Neurosci. 38 (2015) 387-399.

[31] P.B. Gray, A.N. Crittenden, Father Darwin: effects of children on men, viewed from an evolutionary perspective, Fathering. 12 (2014) 121. * Review article of the consequences of fathering for men

[32] K.F. Burn, V.W. Henderson, D. Ames, L. Dennerstein, C. Szoeke, Role of grandparenting in postmenopausal women's cognitive health: results from the Women's Healthy Aging Project., Menopause. 21 (2014) 1069-74.

[33] B. Arpino, V. Bordone, Does grandparenting pay off? The effect of child care on grandparents' cognitive functioning, J. Marriage Fam. 76 (2014) 337-351.

[34] B.S. Hewlett, H.N. Fouts, A.H. Boyette, B.L. Hewlett, Social learning among Congo Basin hunter-gatherers, Philos. Trans. R. Soc. B Biol. Sci. 366 (2011) 1168-1178.

[35] A.A. Volk, Human breastfeeding is not automatic: Why that's so and what it means for human evolution., J. Soc. Evol. Cult. Psychol. 3 (2009) 305-314.

[36] J.C.K. Wells, The role of cultural factors in human breastfeeding: Adaptive behaviour or biopower?, in: K. Bose (Ed.), Ecol. Cult. Nutr. Heal. Dis., Kamla-Raj Enterprises, Delhi, India, 2006: pp. 39-47.

[37] A.V. Bell, K. Hinde, L. Newson, Who was helping? The scope for female cooperative breeding in early Homo, PLoS One. 8 (2013) e83667.

[38] D.W. Shwalb, B.J. Shwalb, M.E. Lamb, Fathers in Cultural Context, Routledge, 2013. 
[39] H. Kokko, M.D. Jennions, Parental investment, sexual selection and sex ratios, J. Evol. Biol. 21 (2008) 919-948.

[40] H. Kokko, M.D. Jennions, Sex differences in parental care, in: N. Royle, P.T. Smiseth, M. Kölliker (Eds.), Evol. Parent. Care, Oxford University Press, Oxford, 2012: pp. 101-116.

** both Kokko and Jennions papers above are extremely important articles in evolutionary biology, clearly describing the problems in the previous literature on parental investment and its allocation between males and females, and some potential solutions

[41] R. Trivers, Parental investment and sexual selection, in: B. Campbell (Ed.), Sex. Sel. Descent Man, 1871-1971, Aldine de Gruyter, New York, 1972: pp. 136-179.

[42] R. Schacht, M. Borgerhoff Mulder, Sex ratio effects on reproductive strategies in humans., R. Soc. Open Sci. 2 (2015) 140402.

[43] M. Gilding, Rampant misattributed paternity: the creation of an urban myth, People Place. 13 (2005) 1-11.

[44] K.G. Anderson, How well does paternity confidence match actual paternity? Evidence from worldwide nonpaternity rates., Curr. Anthropol. 47 (2006) 513-520.

[45] M.H.D. Larmuseau, J. Vanoverbeke, A. Van Geystelen, G. Defraene, N. Vanderheyden, K. Matthys, et al., Low historical rates of cuckoldry in a Western European human population traced by Y-chromosome and genealogical data, Proc. R. Soc. B Biol. Sci. 280 (2013) 20132400-20132400.

[46] J.M. Greeff, J.C. Erasmus, Three hundred years of low non-paternity in a human population., Heredity (Edinb). (2015).

[47] B.I. Strassmann, N.T. Kurapati, B.F. Hug, E.E. Burke, B.W. Gillespie, T.M. Karafet, et al., Religion as a means to assure paternity., Proc. Natl. Acad. Sci. U. S. A. 109 (2012) 9781-5.

[48] B.A. Scelza, Choosy but not chaste: multiple mating in human females., Evol. Anthropol. 22 (2013) 259-69. ** Review article on the benefits of multiple mating to human females, bringing into question the long-standing view that females should be 'coy' and not pursue multiple mates

[49] K.E. Starkweather, R. Hames, A survey of non-classical polyandry., Hum. Nat. 23 (2012) 14972.

[50] R.S. Walker, M. V Flinn, K.R. Hill, Evolutionary history of partible paternity in lowland South America, Proc. Natl. Acad. Sci. 107 (2010) 19195-19200.

[51] K. Hill, A.M. Hurtado, Cooperative breeding in South American hunter-gatherers, Proc. R. Soc. B Biol. Sci. 276 (2009) 3863-3870.

[52] R.M. Ellsworth, D.H. Bailey, K.R. Hill, A.M. Hurtado, R.S. Walker, Relatedness, Co-residence, and Shared Fatherhood among Ache Foragers of Paraguay, Curr. Anthropol. (2014) 647-653. * Gives detail about the potential costs and benefits of partible paternity, the belief that 
children may have more than one father, common in polyandrous south American populations

[53] B.A. Scelza, Female choice and extra-pair paternity in a traditional human population., Biol. Lett. 7 (2011) 889-91.

[54] P.B. Gray, E. Brown, Fatherhood in St. Kitts: patterns and predictors of partnership and paternal dynamics in a Caribbean island, Father. A J. Theory, Res. Pract. about Men as Father. 13 (2015).

[55] S.M. Mattison, B. Scelza, T. Blumenfield, Paternal investment and the positive effects of fathers among the matrilineal Mosuo of Southwest China, Am. Anthropol. 116 (2014) 591610.* Empirical data on fathering and its consequences for child outcomes in a matrilineal population where husbands and wives typically do not coreside

[56] G. Kushnick, B. Hanowell, J.-H. Kim, B. Langstieh, V. Magnano, K. Olah, Experimental evidence for convergent evolution of maternal care heuristics in industrialized and small-scale populations, R. Soc. Open Sci. 2 (2015) 140518-140518. * Cross-cultural study using the same vignette experiment in several different populations, both WEIRD and non-WEIRD, to explore the factors which influence maternal care decisions

[57] G. Kushnick, Access to resources shapes maternal decision making: evidence from a factorial vignette experiment., PLoS One. 8 (2013) e75539.

[58] M.A. Gibson, D.W. Lawson, Applying evolutionary anthropology, Evol. Anthropol. 24 (2015) 3-14.

[59] D.W. Lawson, C. Uggla, Family structure and health in the developing world: what can evolutionary anthropology contribute to population health science?, in: M.A. Gibson, D.W. Lawson (Eds.), Appl. Evol. Anthropol. Darwinian Approaches to Contemp. World Issues, Springer, New York, 2014: pp. 85-118. * Discussion of the benefits and potential pitfalls of applying research in the evolutionary behavioural sciences to real world problems, illustrated with examples of how family structure influences child health 
Box 1: Why do mothers care more than fathers?

Kokko and Jennions $[39,40]$ recently re-examined the question of why mothers, on average, invest more than fathers across the natural world. Trivers' [41] influential work on parental investment suggested two reasons could explain this phenomenon: firstly, greater initial female investment in gametes means they have more to lose should the offspring die; secondly, male-biased sex ratios increase competition for mates among males, which leads to greater mating effort among males and consequently lower parental effort. Kokko and Jennions challenged these arguments, pointing out that the first commits the 'Concorde fallacy': individuals should base decisions about future investment solely on the costs and benefits of that future investment, and not take into consideration past investment. In contrast to Trivers' second argument, they argue that male-biased sex ratios may lead to increased investment in parenting effort, as the odds of winning the competition for a mate are slim, and so the relative value of caring for offspring versus competing for mates increases. Kokko and Jennions suggest the explanation for widespread female-biased care is more complicated than Trivers' original arguments, and may vary between (and within) species, depending on adult sex ratios (which may depend on the impact of parental care on mortality rates), paternity certainty, variance in male reproductive success and the consequences of parental care for offspring outcomes. 
Figure 1: parental or alloparental behaviour is influenced by our species-specific constraints and adaptations, but is also shaped by adaptive responses to ecological conditions and by cultural norms. These three levels can be hard to separate (some cultural models may be the result of adaptive responses to ecological conditions, for example), and there are feedback loops between all three (both ecology and culture influences our genetic make-up). Modified from LeVine et al 2008

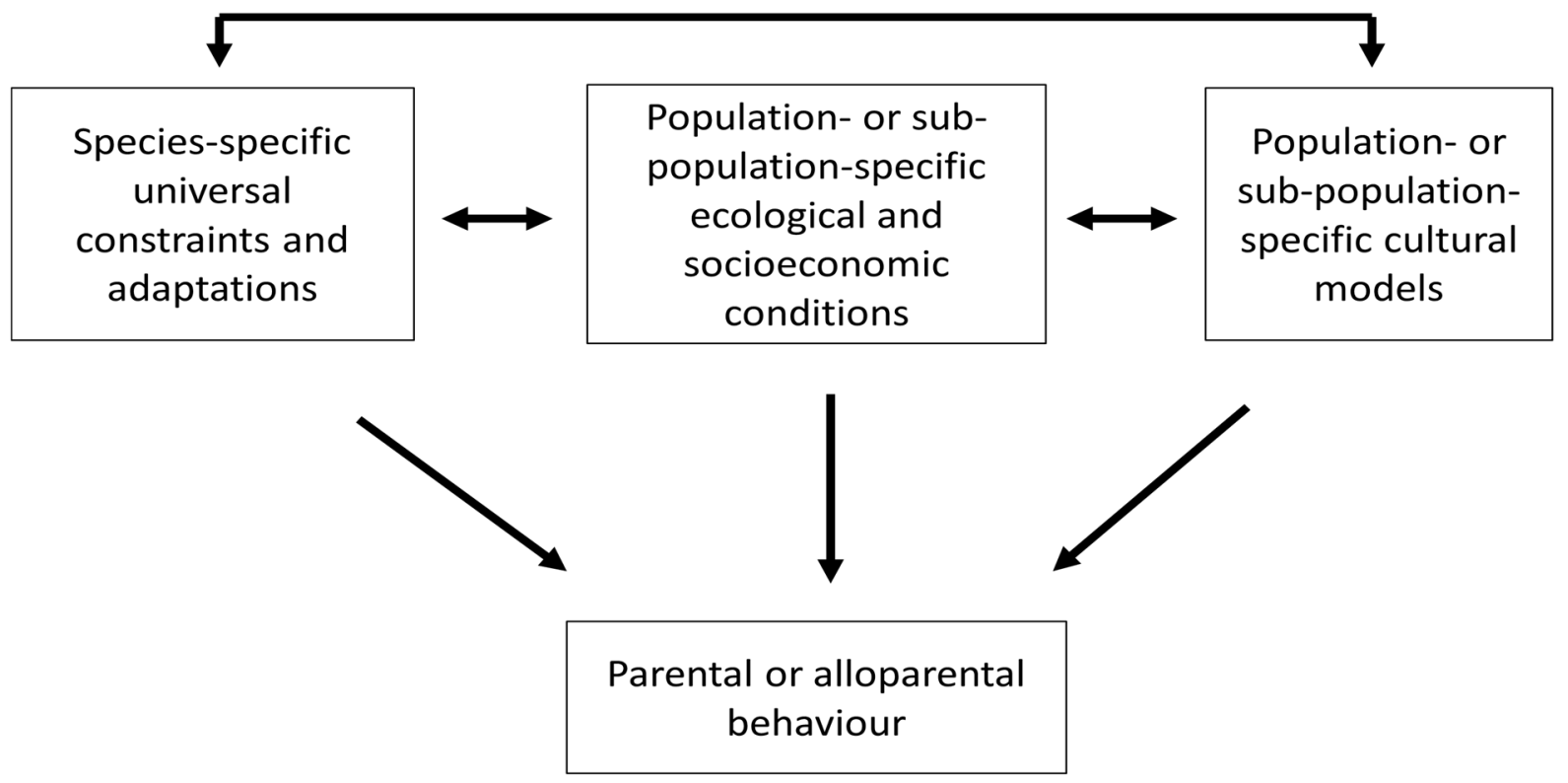


Figure 2: graphical abstract for Kushnick et al 2015 [56], which shows the factors which influence hypothetical maternal care decisions in small-scale (non-WEIRD) versus industrialised (WEIRD) societies (in the large boxes), as well as environmental factors which characterise each type of society

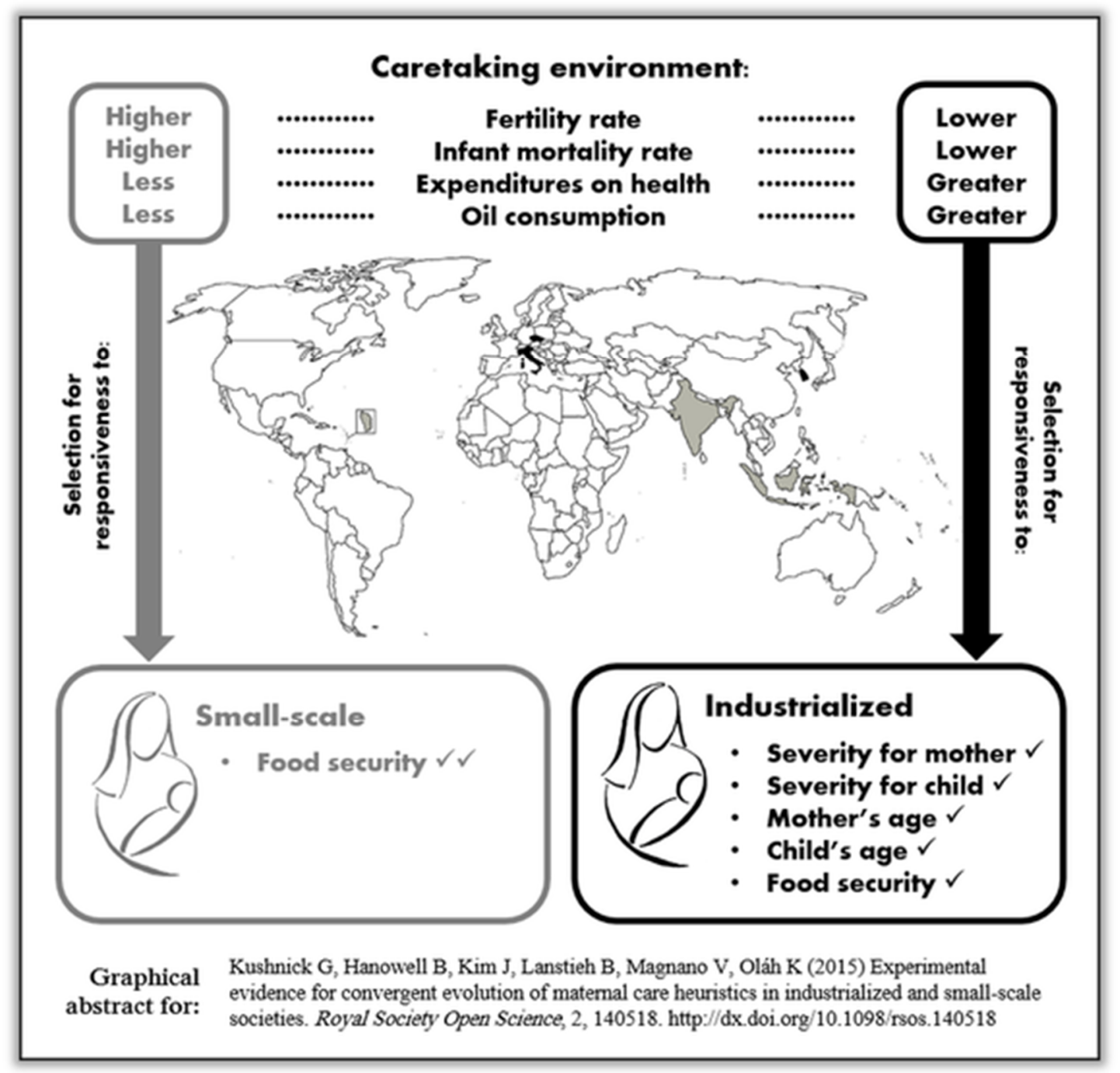

